\title{
Problem gamblers in primary care: can GPs do more?
}

The UK is in the midst of a profound economic decline and the failing economy could be linked to increases in problem gambling as individuals bank on big wins to deal with reducing finances. In primary care settings in the UK, most problem gamblers go unrecognised and their health needs arising from their problem go unaddressed. This may be for various reasons, such as a reluctance to disclose the role of gambling in contributing to negative health impacts. Healthcare professionals' low awareness of problem gambling is linked to their limited knowledge regarding how to identify and assist patients experiencing gamblingrelated harm. It is likely that even where primary health practitioners do identify the existence of gambling-related harm, they regard this as a personal or 'social' problem, rather than a health issue, meaning that the needs of relevant individuals are largely unaddressed. In this editorial we argue the case for why and how GPs should do more to address problem gambling.

\section{EPIDEMIOLOGY AND CONSEQUENCES}

Nearly $70 \%$ of the British population gamble recreationally but problem gambling, defined as 'gambling to a degree that disrupts or damages personal, family or recreational pursuits', 1 has a prevalence of around $0.6 \%$ in Britain ${ }^{2}$ which equates to around 250000 individuals. It is further estimated that $6.5 \%$ of the population is at varying degrees of risk of developing problem gambling in the future. Problem gambling cuts across age, sex, class, and race: although specific social groups, such as young people and particular ethnic minorities are likely to be particularly vulnerable. International research shows that an increase in gambling opportunities will lead to an increase in gambling-related problems ${ }^{3}$ and this ought to be recognised by Britain's health policy makers because
Britain has liberal gambling legislation and a rapidly growing online gambling industry.

Problem gambling can impact negatively on the individual, their family, their employer, local social networks, and wider society. Problem gamblers report high rates of physical and psychiatric complaints: physical problems include various stress-related symptoms and conditions, ${ }^{4}$ and psychiatric comorbidity includes depression, anxiety-spectrum disorders, substance misuse, and personality disorders. ${ }^{5}$

The financial burden of excessive gambling can result in debts and bankruptcy, and some gamblers resort to crime to fund their habit. It has been shown that for every problem gambler, 8 to 10 others (family, friends, and colleagues) are also negatively affected. ${ }^{6}$ Domestic abuse and spousal violence; increased rates of behavioural and emotional problems; and substance abuse among children of gamblers are commonly correlated with problematic gambling behaviour. ${ }^{8}$

\section{WHY SHOULD GPS DO MORE?}

First, problem gamblers have high rates of physical and psychiatric comorbidity, which are often the reasons for presentation to GPs. Second, international research has shown the prevalence of gambling disorders in primary care attendees to be around $6 \% .^{9}$ Third, accurate and easy to use screening tools are available for use in primary care (see below), and there are specialist services that offer effective treatments which GPs can easily access. Fourth, untreated problem gambling will continue to impact negatively on the individual and family, and significantly burden society. Finally, GPs can play a crucial role in the prevention of problems associated with gambling by using screening measures, and offering brief interventions, onward referral, and treatment where appropriate.

The view that more should be done to address problem gambling in primary care (and more widely in the NHS) is not new: The British Medical Association in its publication, Gambling Addiction and its Treatment Within the NHS: a Guide for Healthcare Professionals, ${ }^{10}$ called for all healthcare professionals to be aware of problem gambling and common comorbidities, and specifically highlighted the need for 'education and training ... in the diagnosis, appropriate referral and effective treatment of gambling problems' to be addressed within GP training.

\section{WHAT CAN GPS DO?}

We are not suggesting that GPs screen all patients for problem gambling. However, we do advocate that they screen those who are deemed at high risk, such as those presenting with psychosomatic symptoms, other psychiatric disorders including substance misuse, depression, and anxiety-spectrum disorders, and those reporting financial problems.

Of the various screening questionnaires used, we recommend the Lie/Bet Questionnaire $^{11}$ because of its ease of use. This consists of two questions: 'Have you ever felt the need to bet more and more money?' and 'Have you ever had to lie to people important to you about how much you gamble?' An affirmative response to either question identifies a pathological gambler and calls for further assessment/referral.

Although not validated, another brief three-question tool used in a primary carebased gambling service in Birmingham asks: 'Do you gamble?', 'Do you experience problems with your gambling?', and 'Would you like to talk to someone about your gambling?'. If they answer yes to questions two and three, the GP would then refer in to the more specialist service.

We recommend that, unless resources permit otherwise, GPs refer all those who screen positively for further assessment and specialist treatment. Local addiction services could be the first port of call and/or patients could be sign posted (or 
self-refer) to non-statutory agencies such as GamCare (www.gamcare.org.uk) and GA (www.gamblersanonymous.org.uk). Disappointingly, service provision for problem gamblers within the NHS is very limited. As regards treatment, psychosocial treatments are the mainstay; pharmacotherapies, such as antidepressants, mood stabilisers, and naltrexone, have been tried with some success but none is licensed for use in this specific context.

Attempts to screen and treat problem gamblers in primary care can be feasible and effective: a 3-year pilot project in Birmingham, commissioned by the South Birmingham Primary Care Trust and provided by 'Aquarius' (a leading charity providing drug, alcohol, and gambling services in the Midlands) has been in operation since 2009 (L Rusling, personal communication, 2010). This consists of opportunistic screening and brief intervention in primary care, and onward referral where indicated, and is set up within a local enhanced service for GPs: the first of its kind in Britain.

\section{THE WAY FORWARD}

We acknowledge that there are significant resource implications in developing effective gambling treatment strategies within primary care. Despite this, we believe that primary care practitioners have a key role in helping Britain's problem gamblers.

There are good examples of effective working models relating to the identification and treatment of problem gamblers in primary care, and we would argue that, despite the current state of flux in terms of commissioning health services, this is an opportune time to consider setting up further pilots to expand such services. We can also envisage adapting 'shared care' schemes that already exist for substance misuse service provision, where GPs and addiction specialists work jointly and share the care of their drug misusing patients. As insufficient knowledge and lack of expertise are often cited by GPs as barriers to addressing problem gambling, there is an immediate need for further GP training to raise awareness and equip them in screening, assessing, referring, and/or treating problem gamblers. This is similar to the problems with substance misuse a decade ago, which has now largely been addressed through a national, professionally-driven training programme. ${ }^{12}$

GPs have a crucial role in addressing problem gambling in primary care, both as treatment providers at present and as treatment commissioners in the near future. We hope this paper will help to catalyse further debate among key stakeholders and arouse interest in this largely 'hidden' addiction.

\section{George Sanju,}

Consultant and Senior Research Fellow in Addiction Psychiatry, Solihull Integrated Addiction Services, Birmingham and Solihull Mental Health NHS Foundation Trust, and Honorary Senior Lecturer in Addiction Psychiatry, University of Birmingham, Birmingham.

\section{Clare Gerada,}

Chair of the Royal College of General

Practitioners and GP, London.

\section{Provenance}

Commissioned, not externally peer reviewed.

\section{REFERENCES}

1. Lesieur HR, Rosenthal MD. Pathological gambling: review of the literature (prepared for the American Psychiatric Association Task Force on DSM-IV Committee on disorders of impulse control not elsewhere classified). J Gambling Stud 1991; 7: 5-40.

2. Wardle H, Sproston K, Orford J, et al. The British gambling prevalence survey 2007. London: The Stationery Office, 2007

3. National Research Council, National Academy of Sciences, Committee on the Social and Economic

Impact of Pathological Gambling. Pathological gambling: a critical review. Washington DC: National Academy Press, 1999.

4. Morasco BJ, Pietrzak RH, Blanco C, et al. Health problems and medical utilization associated with gambling disorders: results from the National Epidemiologic Survey on alcohol and related conditions. Psychosom Med 2006; 68: 976-984.

5. Petry NM, Stinson FS, Grant BF. Comorbidity of DSMIV pathological gambling and other psychiatric disorders: results from the National Epidemiologic Survey on Alcohol and Related Conditions. J Clin Psychiat 2005; 66: 564-574.

6. Lobsinger C, Beckett L. Odds on the break even: a practical approach to gambling awareness. Canberra: Relationships Australia, Inc, 1996.

7. Muelleman RL, Denotter T, Wadman MC, et al. Problem gambling in the partner of emergency department patient as a risk factor for intimate partner violence. J Emerg Med 2002; 23: 307-312.

8. Jacobs D F, Marston A R, Singer R D, et al. Children of problem gamblers. Journal Gambling Behaviour 1989; 5: 261-268.

9. Pasternak AV, Fleming MF. Prevalence of gambling disorders in a primary care setting. Arch Fam Med 1999; 8: 515-520.

10. Griffiths MD. Gambling addiction and its treatment within the NHS: a guide for healthcare professionals. London: British Medical Association, 2007.

11. Johnson EE, Hamer R, Nora RM, et al. The Lie/Bet Questionnaire for screening pathological gamblers. Psychol Rep 1997; 80: 83-88.

12. Gerada C, Murnane M. Royal College of General Practitioners certificate in drug misuse. Drugs: Education, Prevention \& Policy 2003; 10: 369-378.

DOI: 10.3399/bjgp11X567027

ADDRESS FOR CORRESPONDENCE

Clare Gerada,

Royal College of General Practitioners,

1 Bow Churchyard, London

EC4M 9DQ

E-mail: chairman@rcgp.org.uk 